УДК 338.001.36

\title{
ПРАКТИКА ПРИМЕНЕНИЯ ЕРС(М)-КОНТРАКТОВ КРУПНЕЙШИМИ ИГРОКАМИ МЕЖДУНАРОДНОГО РЫНКА НЕФТЕГАЗОВЫХ ИНЖИНИРИНГОВЫХ УСЛУГ
}

Карачурина Гузель Гизаровна к.э.н., доцент кафедры «Экономика и стратегическое развитие» Тупикина Полина Сергеевна магистрант ФГБОУ ВО «Уфимский государственный нефтяной технический университет»

\begin{abstract}
Аннотация: В статье анализируется рынок инжиниринговых услуг, в частности опыт применения ЕРС(М)-контрактов международными нефтегазовыми компаниями, проведен анализ крупных зарубежных игроков отрасли в сравнении с отечественными. Отмечены меры повышения эффективности и конкурентоспособности ЕРС(М)-контракторов Российской Федерации для перспективного развития нефтегазового инжиниринга в стране.
\end{abstract}

Ключевые слова: мировой рынок, нефтегазовый инжиниринг, ЕРС(М)контракт, конкурентоспособность, перспективы развития.

\section{PRACTICE OF APPLICATION OF EPC(M)-CONTRACTS BY THE LARGEST PLAYERS OF THE INTERNATIONAL MARKET OF OIL AND GAS ENGINEERING SERVICES}

\section{Karachurina Guzel Gizarovna Tupikina Polina Sergeevna}

\begin{abstract}
The article analyzes the market of engineering services, in particular the experience of applying EPC(M)-contracts by international oil and gas companies, and analyzes major foreign players in the industry in comparison with domestic ones. Measures to improve the efficiency and competitiveness of EPC(M)contractors of the Russian Federation for the long-term development of oil and gas engineering in the country are noted.
\end{abstract}

Key words: global market, oil and gas engineering, EPC(M)-contract, competitiveness, development prospects. 
Рынок инжиниринговых услуг является важной составляющей любой развитой экономики и занимает первое место в отрасли глобальной предпринимательской деятельности по размеру рынка и двенадцатое место по его величине. Сейчас в отрасли задействовано 433354 предприятий, количество занятых 2366351 человек по всему миру.

По данным Международной федерации инженеров-консультантов (FIDIC), являющейся глобальным представительным органом и объединяющей более миллиона инженеров-консультантов и 40000 фирм в ста странах мира, в 2010 году мировой объем рынка инжиниринговых услуг составил 825 506,5 млн. долларов США. В период с 2010 года по 2019 год рынок рос в среднем на 1,1\% и на текущий момент объем мирового рынка достиг 1398815,7 млн. долларов США (рис. 1), что является следствием не только роста количества заключаемых контрактов, но и роста объемов работ в рамках одного проекта [1].

Однако пандемия COVID-19 поразила отрасль, создав беспрецедентные экономические условия и по оценкам IBISWorld ожидается, что размер рынка глобальных инжиниринговых услуг снизится на -7,7\% в 2021 году.

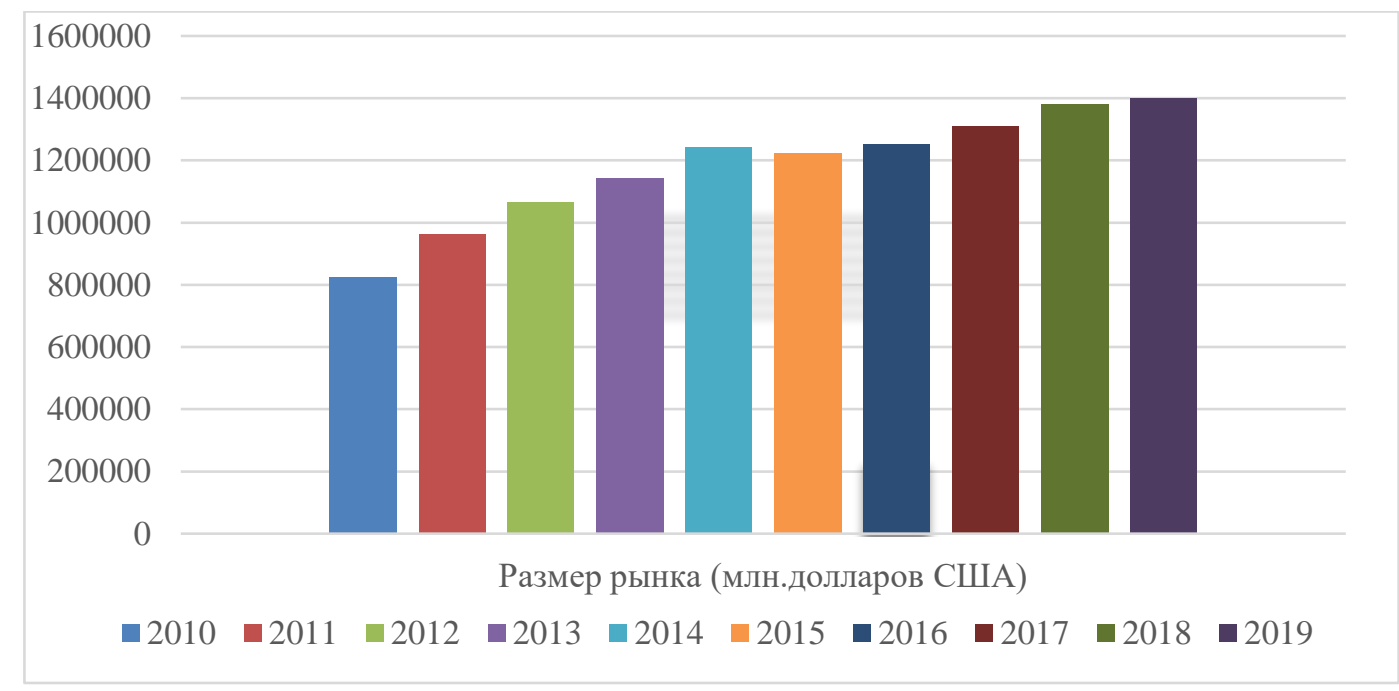

\section{Рис. 1. Объем мирового рынка инжиниринговых услуг 2010-2019 гг.}

Источник: составлено автором по материалам Global Engineering Services 2020. - N.Y.: USA, IBISWorld, 2020.

В настоящее время основную долю мирового рынка инжиниринговых услуг (41\%) составляет нефтегазовая и нефтеперерабатывающая промышленность, 21\% приходится на отрасль электроэнергетики и $15 \%$ на 
химическую промышленность (рис. 2) [2]. Инжиниринговые компании нефтегазовой отрасли занимаются деятельностью, связанной с разведкой, разработкой и обустройством месторождений; созданием и ремонтом объектов сбора, подготовки, транспортировки и хранения углеводородов; геофизикой и бурением скважин, повышением отдачи пластов, в том числе выполнением расчетно-проектных работ, поставкой необходимого технического оборудования, монтажно-строительными работами, а также сервисными и пусконаладочными работами.

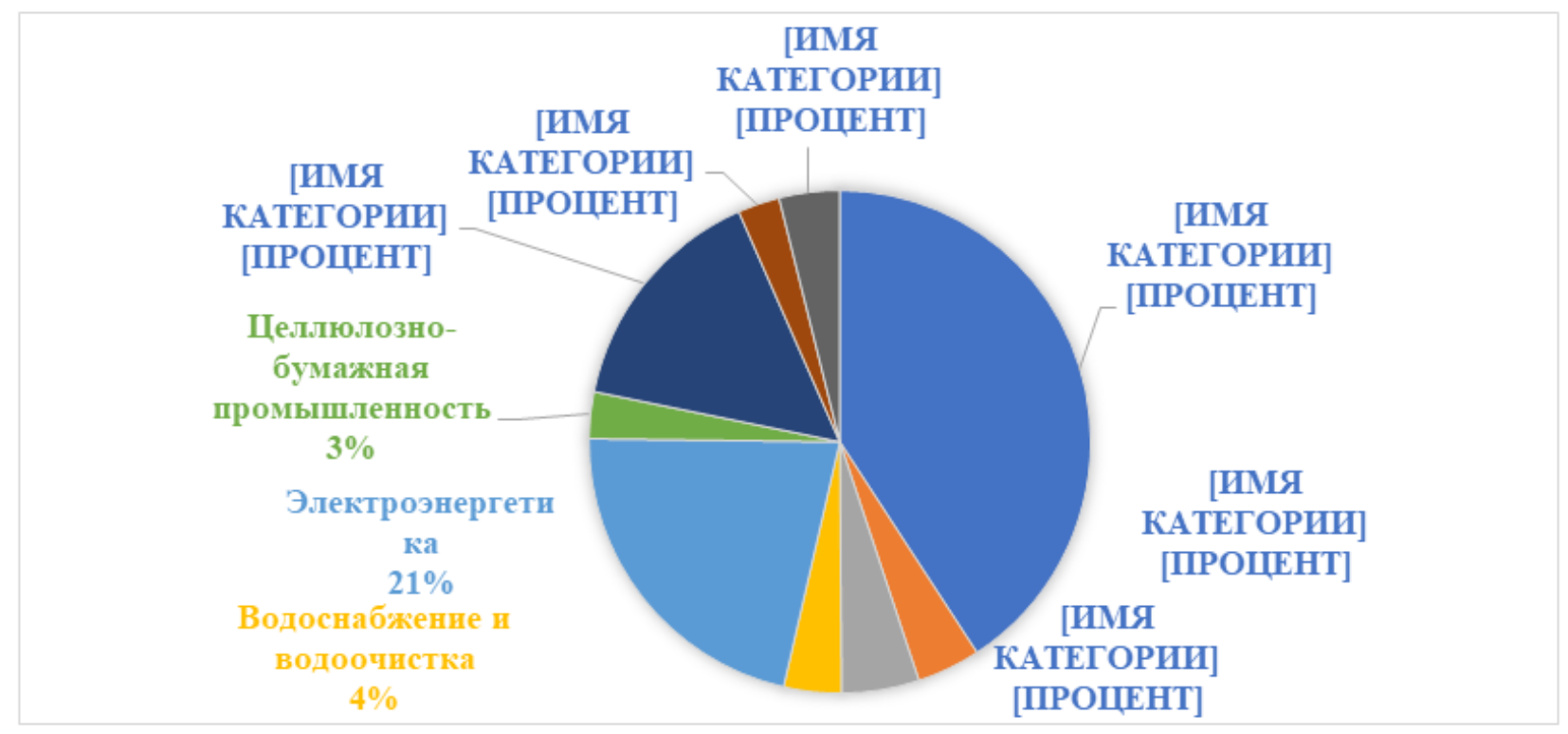

\section{Рис. 2. Распределение мирового рынка инжиниринговых услуг по отраслям экономики в 2019г.}

Источник: составлено автором по материалам UNCTAD Handbook of Statistics 2020. - N.Y. \& Geneva: UN, 2020.

Увеличение масштабов добычи нефти и газа, внедрение новейших отраслевых технологий, а также назревшая потребность в модернизации производственных фондов вызывают целый ряд новых масштабных проектов в сфере капитального строительства по разработке месторождений, развитию нефтегазотранспортной инфраструктуры, возведению перерабатывающих и химических заводов. В связи с этим ведущие компании нефтегазового комплекса, стремящиеся к достижению максимальной эффективности, вынуждены пересматривать и оптимизировать сложившиеся подходы к реализации капитальных проектов. На ранних стадиях реализации важным 
становится определение контрактной стратегии, то есть выбора договорной структуры (типы подрядчиков, виды, последовательность заключения и взаимосвязь договоров), которая позволит реализовать проект в кратчайшие сроки, с наименьшими затратами и с максимально эффективным управлением рисками. При выборе контрактной стратегии учитывается множество факторов: место расположения строительной площадки, вид строящегося объекта, источник финансирования (собственные средства инвестора, строительный заем, проектное финансирование и т.д.), тип строительства («гринфилд», «браунфилд», реконструкция, расширение, модернизация), конъюнктура на рынке подрядных услуг, соотношение компетенций заказчика и подрядчика в области управления строительством, характеристики потенциальных контрагентов и другие [3, стр. 6].

Если говорить о существующих на сегодняшний день формах инжиниринговых контрактов, следует отметить, что при обращении заказчика в инжиниринговую компанию рассматриваются контакты видов: TDBB (Traditional Design-Bid-Building), PCM (Project, Construction, Management), EPC (Engineering, Procurement, Construction), EPCM (Engineering, Procurement, Construction, Management). 80\% крупнейших проектов в мире выполняется по модели ЕРС(М) - лучшей международной практике заключения контрактов. Данный формат позволяет обеспечить заказчику фиксированную стоимость проекта и перевести максимум ответственности на единого подрядчика, включая большинство рисков, непредвиденные затраты и издержки.

Рост объемов инжиниринговых услуг, их диверсификация и нарастание конкуренции на международных рынках усиливают потребность в их регулировании и согласовании на основе двусторонних межгосударственных соглашений и многостороннего регулирования. Типовые шаблоны ЕРС(М)контрактов разрабатываются Международной федерацией инженеровконсультантов (FIDIC), Европейской ассоциацией машиностроительной промышленности (Orgalime), Международной торговой палатой (ICC), Японской ассоциацией по развитию инженерного дела (ENAA) и Международным институтом инженеров-строителей (комплект типовых форм EPC(M)-контрактов ICE и ЕСС) [4].

В последние несколько лет конкуренция в нефтегазовом секторе резко обострилась, особенно на Ближнем Востоке, поскольку количество крупных контрактов сокращается, в то время как основные игроки борются за несколько контрактов на стадии разработки. Это привело к дополнительному росту 
ЕРС(М)-контактов, так как компании должны быть готовыми к постоянно меняющимся требованиям отрасли.

Анализ крупнейших международных подрядчиков, применяющих ЕРС(М)-контракты для осуществления деятельности в нефтегазовой отрасли (табл. 1) показал, что на лидирующих позициях в применении данного типа договорных отношений находятся промышленно развитые страны [5]. Это обусловлено в первую очередь глобальным притоком инвестиций на рынок, высокой прибыльностью контрактов и привлекательным состоянием экономики для реализации проектов. Также рынок инжиниринга нефтегазовой отрасли в значительной степени зависит от рынка разведки и добычи нефти и газа. Так, по данным UNCTAD, приток прямых иностранных инвестиций в экономику США в 2019 году составил 246 млрд. долларов (1 место в мире), в Великобританию - 59 млрд. долларов (8 место в мире).

Таблица 1

Крупнейшие международные ЕРС(М)-контракторы нефтегазовой отрасли по состоянию на 2019г.

\begin{tabular}{|l|l|l|l|l|}
\hline № & Название компании & $\begin{array}{l}\text { Страна } \\
\text { базирования }\end{array}$ & $\begin{array}{l}\text { Объем реализации в } \\
\text { 2019г., млн. долл. } \\
\text { США }\end{array}$ & $\begin{array}{l}\text { Численность } \\
\text { персонала, чел. }\end{array}$ \\
\hline 1 & Bechel & США & 21800 & 55000 \\
\hline 2 & $\begin{array}{l}\text { Hyundai Engineering } \\
\text { Construction }\end{array}$ & Южная Корея & 15596 & 5759 \\
\hline 4 & FLUOR Corp. & США & 14348 & 53349 \\
\hline 5 & Technip FMC & Великобритания & 13409,1 & 37000 \\
\hline 6 & Wood & Италия & 10886 & 34000 \\
\hline 7 & $\begin{array}{l}\text { GS Engineering \& } \\
\text { Construction } \\
\text { Corporation }\end{array}$ & Великобритания & 9990 & 55000 \\
\hline 8 & Юаelim Industrial & Южная Корея & 9402 & 6831 \\
\hline 9 & $\begin{array}{l}\text { Daewoo Engineering } \\
\& \text { Construction Co., } \\
\text { Ltd. }\end{array}$ & Южная Корея & 7809 & 7523 \\
\hline 10 & $\begin{array}{l}\text { SK Engineering \& } \\
\text { Construction }\end{array}$ & Южная Корея & 7080 & 6211 \\
\hline 11 & $\begin{array}{l}\text { Samsung } \\
\text { Engineering }\end{array}$ & Южная Корея & 5748 & 3337 \\
\hline 12 & KBR & США & 5639 & 5566 \\
\hline
\end{tabular}




\begin{tabular}{|l|l|l|l|l|}
\hline \hline 13 & Técnicas Reunidas & Испания & 5622 & 9461 \\
\hline 14 & Petrofac & Великобритания & 5530 & 11500 \\
\hline 15 & Bilfinger & Германия & 5176,93 & 35905 \\
\hline
\end{tabular}

Источник: составлено автором по материалам Oil \& Gas Industry’s First Fullstream Business Platform. - EnergyDais, 2018.

Американская компания по проектированию, снабжению, строительству и управлению проектами «Bechtel» занимает первое место в списке крупнейших ЕРС(М)-компаний в мире по объему выручки в 2019 году, являясь одной из крупнейших частных компаний США. За последние 5 лет «Bechtel» успешно завершила 14 крупномасштабных линий по производству сжиженного природного газа для крупных энергетических компаний, таких как «Cheniere» (NYSE: LNG), «Chevron» (NYSE: CVX), «ConocoPhillips» (NYSE: COP) и других. В авторитетном издании «ENR» (Engineering News-Record), ежегодно публикующим рейтинги международных компаний, «Bechel» заняла 13 место в 2018 году и 17 место в 2019 году в «ТОП-250 международных подрядчиков» (TOP-250 International Contractor). Компании «Нyundai Engineering \& Construction», «FLUOR Corp.», «Technip FMC», «Saipem» также находятся на лидирующих позициях рейтинга [6].

Рынок инжиниринга в России по масштабам значительно уступает аналогичным рынкам зарубежных стран, однако находится в стадии активного формирования. Первым документом, направленным на развитие и поддержку рынка инжиниринговых услуг, является Распоряжение Правительства РФ от 23 июля 2013 года №1300-Р об утверждении плана мероприятий («дорожной карты») [7]. Документ должен был обеспечить значительный рост индустрии инжиниринга, диверсифицировать его по отраслям экономики и создать национальных лидеров в области ЕРС(М)-контрактов к 2018 году.

Оценивая контрольные показатели плана мероприятий (объем внутреннего рынка инжиниринга, доля ЕРС(М)-контрактов в структуре, доля малого и среднего бизнеса, количество совместных зарубежных предприятий), можно отметить успешную реализацию целей документа. Так, на сегодняшний день объем внутреннего рынка инжиниринговых услуг составляет 2,8 трлн. рублей, превышая среднемировой темп роста практически в 2 раза, доля EPC(M)-контактов в структуре внутреннего рынка - 30\% [8].

По данным Министерства промышленности и торговли РФ, до 70\% выручки в инжиниринге приходится на крупные компании нефтегазового сектора, около $25 \%$ - на электроэнергетику. В таблице 2 приведены 
крупнейшие компании рынка российского нефтегазового инжиниринга, применяющие практику ЕРС(М)-контактов [9]. Компании ранжированы по объему реализации в 2019 году в миллионах рублей. Для сопоставления с международными участниками рынка произведен расчет объемов реализации в миллионы долларов США по курсу на сегодняшний день.

Таблица 2

Крупнейшие российские ЕРС(М)-контракторы нефтегазовой отрасли по состоянию на 2019г.

\begin{tabular}{|c|c|c|c|c|c|c|c|}
\hline № & $\begin{array}{l}\text { Название } \\
\text { компании }\end{array}$ & $\begin{array}{l}\text { Объем } \\
\text { реализации } \\
\text { в 2018г., } \\
\text { млн. } \\
\text { рублей }\end{array}$ & $\begin{array}{l}\text { Объем } \\
\text { реализаци } \\
\text { и } \\
2019 \text { г., } \\
\text { млн. } \\
\text { рублей }\end{array}$ & $\begin{array}{l}\text { Объем } \\
\text { реализаци } \\
\text { и } \\
2019 \text { в., } \\
\text { млн. } \\
\text { долл. } \\
\text { США }\end{array}$ & $\begin{array}{l}\text { Темп } \\
\text { ы } \\
\text { роста, } \\
\%\end{array}$ & $\begin{array}{l}\text { Место в } \\
\text { рейтинге } \\
\text { ТОР-250 } \\
\text { Internationa } \\
1 \text { Contractor } \\
\text { в 2019г. }\end{array}$ & $\begin{array}{l}\text { Место } \\
\text { в } \\
\text { рейтин } \\
\text { ге } \\
\text { RAEX- } \\
600\end{array}$ \\
\hline 1 & НИПИГАЗ & 114720,9 & 256260,9 & 3503,2 & 123,4 & 96 & - \\
\hline 2 & Стройгазмонтаж & 304102,8 & 193609,7 & 2996,1 & $-36,3$ & - & 80 \\
\hline 3 & $\begin{array}{l}\text { Стройтранснефт } \\
\text { егаз }\end{array}$ & 186530,4 & 164178,8 & 2540,7 & -12 & - & 101 \\
\hline 4 & Велесстрой & 75758,1 & 129315,3 & 2001,2 & 70,7 & 157 & 125 \\
\hline 5 & Газартстрой & 36256,8 & 52078,4 & 805,9 & 43,6 & - & 293 \\
\hline
\end{tabular}

Источник: составлено автором по материалам 10 крупнейших компаний в сфере инжиниринга и промышленного-инфраструктурного строительства. RAEX-600 Rating Review, 2020.

Анализ современного состояния российского рынка инжиниринговых услуг в нефтегазовой отрасли показал присутствие относительно небольшого числа компаний, что в первую очередь говорит о высокой степени его монополизации. Крупнейшие компании США («Bechel», «FLUOR Corp.») оказывают менее 5\% услуг на рынке нефтегазового инжиниринга, тогда как в России на «НИПИГАЗ» и «Стройгазмонтаж» приходится около 25\% в денежном эквиваленте. Данное обстоятельство связано с тем, что большую часть заказов в России составляют масштабные проекты, где заказчиком выступают государство и госкомпании.

Крупные игроки рынка нефтегазового инжиниринга также, как и зарубежные, применяют опыт $\mathrm{EPC(M)-контрактов.} \mathrm{На} \mathrm{данный} \mathrm{момент}$ «НИПИГАЗ» участвует в реализации крупнейшего в России нефтехимического 
комплекса «ЗапСибНефтехим» СИБУРа, а также в строительстве Амурского газоперерабатывающего завода «Газпром» стоимостью 790 млрд. рублей именно по данной модели контрактирования, демонстрируя максимальный темп роста среди всех игроков на рынке. Также «НИПИГАЗ» является единственной российской компанией, вошедшей в сотню лучших мировых участников рынка инжиниринга по версии ENR (TOP-250 International Contractor) [10].

Однако при сравнении российских компаний с мировыми, сложно не отметить, что объем реализации услуг в 2019 в млн. долларов США в несколько раз ниже. Эффективные западные компании заметно потеснили на мировых рынках российские, и, учитывая современную политическую и экономическую ситуацию, а также возрастающий рост сложности, масштаба и технологической насыщенности крупных проектов, существует значительное отставание внешних и внутренних российских инжиниринговых рынков в нефтегазовой отрасли. Наблюдается не только количественный, но и качественный разрыв между отечественными компаниями и их конкурентами на мировой арене.

По оценкам самих участников рынка к первоочередным мерам повышения конкурентоспособности российских инжиниринговых компаний относятся: стабилизация финансово-экономической политики $(68 \%$ респондентов); потенциальное снижение налоговых ставок или введение налоговых льгот (45\%); использование новых инструментов и механизмов поддержки индустрии (32\%); стимулирование иностранных компаний к созданию локальных центров на территории РФ (15\%). Достаточно востребованы среди руководства инжиниринговых компаний такие меры как совершенствование вузовских программ подготовки кадров для сферы инжиниринга и промышленного дизайна; обеспечение доступа к средне- и долгосрочному кредитованию инвестиционных проектов (от трех лет и выше); развитие программы импортозамещения в сфере инжиниринга, включая предоставление субсидий [11].

Для решения поставленных перед отраслью необходима координация усилий государства и крупнейших игроков на рынке нефтегазовых инжиниринговых услуг. Энергетическая стратегия РФ на период до 2035 года, утвержденная 9 июня 2020 года [12], предусматривает развитие производства сжиженного природного газа; формирование СПГ-кластера на полуострове Ямал, Гыдан и шести нефтегазохимических кластеров; развитие газотранспортной структуры в Восточной Сибири и на Дальнем Востоке; повышение инновационной активности компаний топливно-энергетического 
комплекса. Обновленный 11 июня 2020 года Правительством РФ план мероприятий в области инжиниринга («дорожная карта 2.0») призван увеличить объем внутреннего рынка на 1,1 трлн. рублей до 2025 года, применяя в 40\% случаев высокотехнологичные ЕРС(М)-контакты.

Реализация указанных мероприятий создаст благоприятную обстановку для игроков рынка нефтегазового инжиниринга и повысит инвестиционную привлекательность отрасли в ближайшей перспективе. Однако на микроуровне компании вынуждены справляться с высокими рисками, непреодолимыми барьерами входа на рынок, длительными инвестиционными периодами и большими объемами первоначальных инвестиций.

\section{Список литературы}

1. Global Engineering Services 2020. - N.Y.: USA, IBISWorld, 2020.

2. UNCTAD Handbook of Statistics 2020. - N.Y. \& Geneva: UN, 2020.

3. Липавский В.Б. «Структурирование, заключение и исполнение ЕРС и EPC(М)-контрактов // OST LEGAL law firm - 2015. 2017.

4. Guide to practice, the business of a professional services firm. - FIDIC,

5. Oil \& Gas Industry's First Fullstream Business Platform. - EnergyDais, 2018.

6. Официальный сайт компании Bechel. [Электронный ресурс] - Режим доступа: https://www.bechtel.com (Дата обращения 15.12.2020).

7. Распоряжение Правительства РФ от 23 июля 2013 года №1300-Р «Об утверждении плана мероприятий («дорожной карты») в области инжиниринга и промышленного дизайна».

8. Распоряжение Правительства РФ от 11 июня 2020 года №1546-р «Об утверждении плана мероприятий («дорожной карты 2.0) и промышленного дизайна».

9. 10 крупнейших компаний в сфере инжиниринга и промышленногоинфраструктурного строительства. - RAEX-600 Rating Review, 2020.

10. Handbook of The Top 250 Global Contractors. - Brussels: EU, ENR, 2019.

11. Итоги пилотного обследования деловой активности в секторе инжиниринговых услуг и промышленного дизайна. - ИСИЭЗ НИУ ВШЭ, 2015.

12. Распоряжение Правительства РФ от 9 июня 2020 года №1523-р «Об утверждении Энергетической стратегии Российской Федерации на период до 2035 года».

(C) Г. Г. Карачурина, П. С. Тупикина, 2020 